\title{
From a Magnet to a Heat Pump
}

Kristina Navickaitė*, Henrique Neves Bez, Kurt Engelbrecht, Christian R. H. Bahl

Technical University of Denmark, Department of Energy Conversion and Storage Frederiksborgvej 399, 4000 Roskilde, Denmark

*Corresponding author: knav@dtu.dk

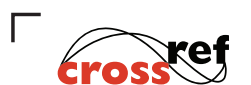

http://dx.doi.org/10.5755/j01.sace.14.1.15927
The magnetocaloric effect (MCE) is the thermal response of a magnetic material to an applied magnetic field. Magnetic cooling is a promising alternative to conventional vapor compression technology in near room temperature applications and has experienced significant developments over the last five years. Although further improvements are necessary before the technology can be commercialized. Researchers were mainly focused on the development of materials and optimization of a flow system in order to increase the efficiency of magnetic heat pumps. The project, presented in this paper, is devoted to the improvement of heat pump and cooling technologies through simple tests of prospective regenerator designs. A brief literature review and expected results are presented in the paper. It is mainly focused on MCE technologies and provides a brief introduction to the magnetic cooling as an alternative for conventional vapor compression technology.

KEYWORDS: heat pump, heat transfer, magnetic refrigeration, magnetocaloric effect, test device modelling.

The magnetocaloric effect (MCE) was discovered by French and Swiss physicists Weiss and Piccard (Smith et al. 2012). In the mid-1920s Debye and Giauque proposed a method of adiabatic demagnetization to reach very low temperatures (Smith et al. 2012). The discovery of magnetocaloric materials $(\mathrm{MCM})$ with Curie temperatures $\left(T_{c}\right)$ near room temperature (RT) has opened an opportunity for magnetic refrigeration (MR) to become an alternative to conventional vapor compression devices. Furthermore, MR technology is environmentally friendly since it has zero vapor pressure, no Ozone Depletion Potential (ODP), no direct Global Warming Potential (GWP), it has potential to be more compact layout since the working material is solid, and has the potential to work more silently than conventional compressors (Bahl et al. 2008, Barbosa et al. 2014, Engelbrecht et al. 2011, Eriksen et al. 2015, Lei et al. 2016, Smith et al. 2012).

The MC cooling technique is based on the thermal response of a magnetic material when magnetized/demagnetized, such as a temperature increases when the field is increased and vice versa. The isothermal entropy change is negative upon magnetization and positive upon demagnetization, see Fig. 1. This scenario is valid when an ordinary MCE takes place and is analogous to the negative change in entropy associated with the isothermal compression of a gas.

MR near RT is a desirable, but at the same time technically challenging idea. Challenges are related to device engineering. Barclay et al. (1981) patented the active magnetocaloric regenerator (AMR) with its own 'distributed refrigeration' cycle which can provide refrigeration over a temperature span that is much larger than the adiabatic temperature change of the material. Nevertheless, an efficient AMR device requires a large magnetic field. Rowe et al. (2006) concluded that

\section{Introduction}

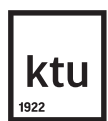

Journal of Sustainable Architecture and Civil Engineering Vol. 1 / No. 14 / 2016 pp. 73-79 DOI 10.5755/j01.sace.14.1.15927 (C) Kaunas University of Technology 
Fig. 1

An MR material with randomly oriented spins is magnetized the temperature of

a material increases adiabatically (a) and then entropy decreases under isothermal conditions (b)

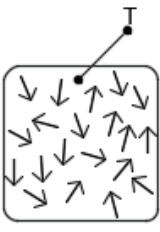

$\mathrm{T} \uparrow$

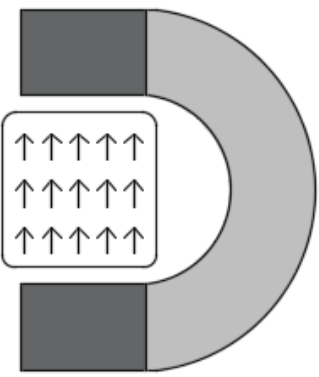

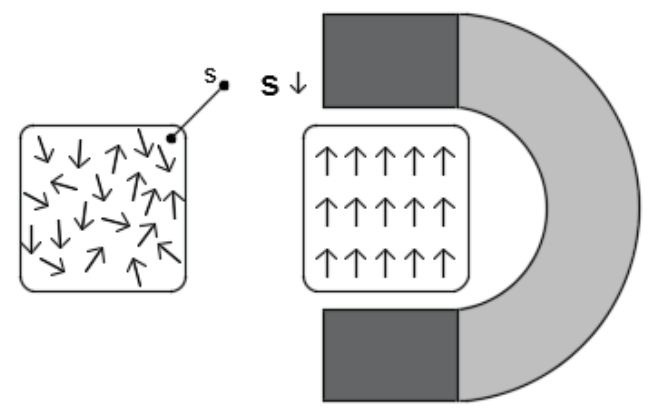

b the lower magnetic field might be compensated by increasing the operating frequency. However, Nielsen and Engelbrecht (2012) showed that in case of a long AMR $(200 \mathrm{~mm})$ the importance of the thermal conductivity increases when a device is operated at a high frequency - the higher the operating frequency, the higher the thermal conductivity is necessary.

Seeking to optimize the configuration of machines, attention is mainly paid to the performance of it. There are several ways to increase the efficiency of an MR such as optimizing the flow system, optimizing the magnet assembly, improving regenerator geometry, and investigating new MCMs, etc. Nevertheless, the main attention of other researchers is paid on the investigation of materials such as changing their composition (Kaštil et al. 2013).

On the other hand, to build an MR with a high COP, an efficient heat exchanger is required. Since the adiabatic temperature span in the MCE (in the magnetic field up to $1.5 \mathrm{~T}$ ) is limited to a maximum $5.8 \mathrm{~K}$ per one layer of MCM, conventional heat exchangers are not sufficient to be directly implemented in this application. The temperature span is required to be at least $30 \mathrm{~K}$ for conventional devices (Kitanovski et al. 2015). This suggests considering a novel concept of heat exchanger. It has long been a goal to design a heat exchanger with a high heat transfer rate and low pressure drop, but now it turned to be crucially important for the successful implementation of novel cooling technologies.

Discovered compositions are available in a variety of shapes and packing of new materials should be tested before applying them in larger and more complex prototypes. The properties of a series of such MCMs are tested in a vertically oriented versatile device - the test machine, see Fig. 2. It is designed in a way to allow the variation and control of many experimental parameters. A brief introduction to the main parts and operation of the test machine are given in this paper, more detailed description of the device and operational conditions are given in Bahl et al. (2008) and Engelbrecht et al. (2012). The device is built in a temperature controlled cabinet. The hot reservoir (1) is placed above the regenerator (2) and is linked to the forced convection heat exchanger (HEX) (3) and the cold reservoir (4) (below the regenerator) is covered by thermal insulation (not shown). A Halbach cylinder permanent magnet is used as a magnetic field source, with an average flux density in the bore of $1.03 \mathrm{~T}$. The temperature of the hot end $\left(T_{\text {hot }}\right)$ is controlled via the ambient (air inside the cabinet) temperature.

During operation a regenerator is moved vertically by a stepper motor while the magnet is kept in a stationary position (see Fig. 3). Magnetization and demagnetization of the MCM is achieved in this way and a temperature span across the thermal reservoirs is built up. The heat transfer fluid is moved through the regenerator by mean of a displacer in the cold end. The entire device is in thermal contact with the same ambient air i.e. hot end is thermally linked to the ambient via a forced convection heat exchanger while the cold end is thermally insulated using foam tubing. 
The test machine can be operated in different combinations of various parameters, such as a different piston (displacer) stroke (amplitude) and velocity. The heat transfer fluid flow is provided by pushing the piston backwards and forwards. In this manner the fluid velocity and volume of the flow can be controlled. The velocity of the fluid resents the ratio of the thermal capacity of the fluid that moves into regenerator to the thermal capacity of the solid regenerator material. The expression to define utilization $(\phi)$ is given below:

$$
\phi=\frac{\dot{m}_{f} c_{f}}{m_{s} c_{s}}
$$

where:

$\dot{m}_{f}$ - mass of the fluid pushed through the regenerator in one direction;

$c_{f}$ and $c_{s}$ - specific heat of the fluid and the solid, respectively;

$m_{\mathrm{s}}$ - mass of the solid regenerator (Neves Bez et al. 2016).

To find the optimal working point of the MCM, $T_{\text {hot }}$ is set slightly above the $T_{\mathrm{C}}$ of the working material and series of tests are run under the following conditions: directly affects utilization, which rep-

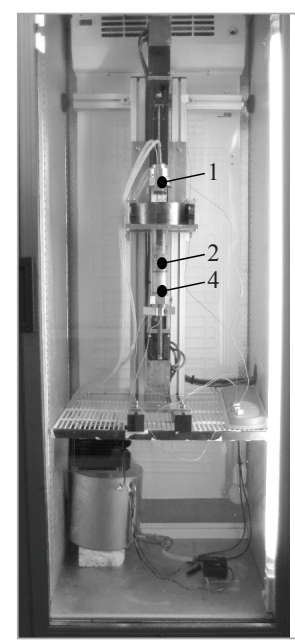

a

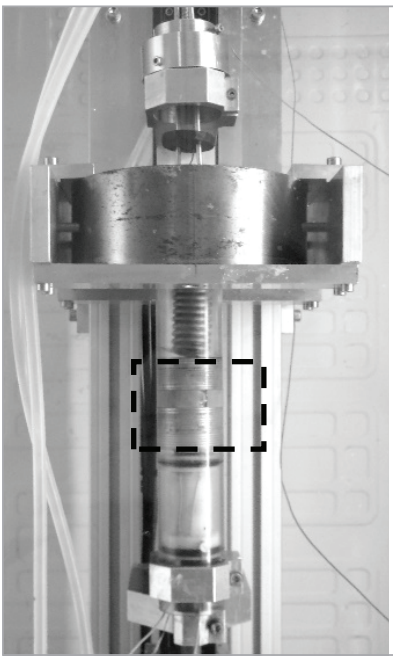

a

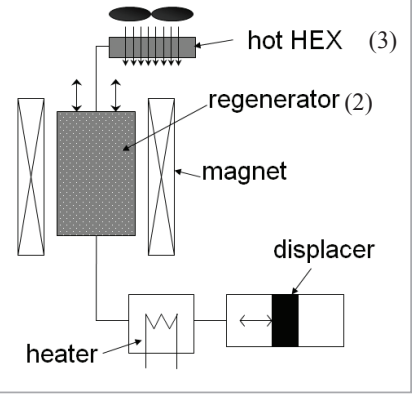

b

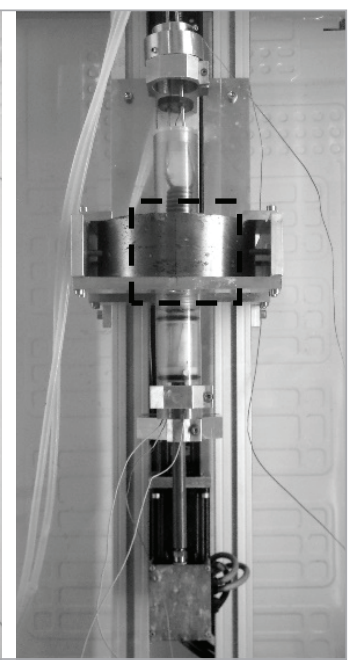

1 At different piston amplitudes, when the utilization (Eq. 1) of a regenerator is known. The sample is tested at the same temperature (slightly above the $T_{c}$ ) and piston velocity conditions. The point where the temperature span is the highest is selected to be the optimal piston amplitude for the remaining tests of the same regenerator.

2 At different piston velocities, when the optimal piston amplitude is known. The sample is tested at the same temperature (same as at the first step) and piston amplitude conditions. The point where the temperature span is at the peak is selected to be the optimal piston velocity for the remaining tests of the same regenerator.

3 At the different temperature range, when the piston amplitude and velocity is constant. 3 When working point is known, a test against temperature change is made in order to find the peak of the temperature span of the tested sample.

Two types of regenerators have been tested in the test machine. The parallel plate regenerator is shown in the Fig. 4. a). The irregular particle regenerator is shown in Fig. 4 b) and c). The MCM and their characteristics are not discussed further in this paper. More information about the both types of the regenerators might be found in Bahl et al. (2016) and Neves Bez et al. (2016), respectively. The results for three regenerators, in the form of irregular particles (see Fig. 4 b and c) are presented in this paper. All of the presented regenerators were bonded with a small amount of epoxy
Fig. 2

A photo of the test machine installed in the temperature controlled cabinet (a) and the schematic drawing (b) (Engelbrecht et al. 2012)

Fig. 3

The test machine with the magnetic regenerator a) outside and $b$ ) inside the magnet 
Fig. 4

The MCM regenerator a) stacked plate regenerator

b) top view and c) side view. Geometry of the housing of the regenerators $\varnothing \sim 38 \mathrm{~mm}$ (outer) and $\mathrm{h}=40 \mathrm{~mm}$.
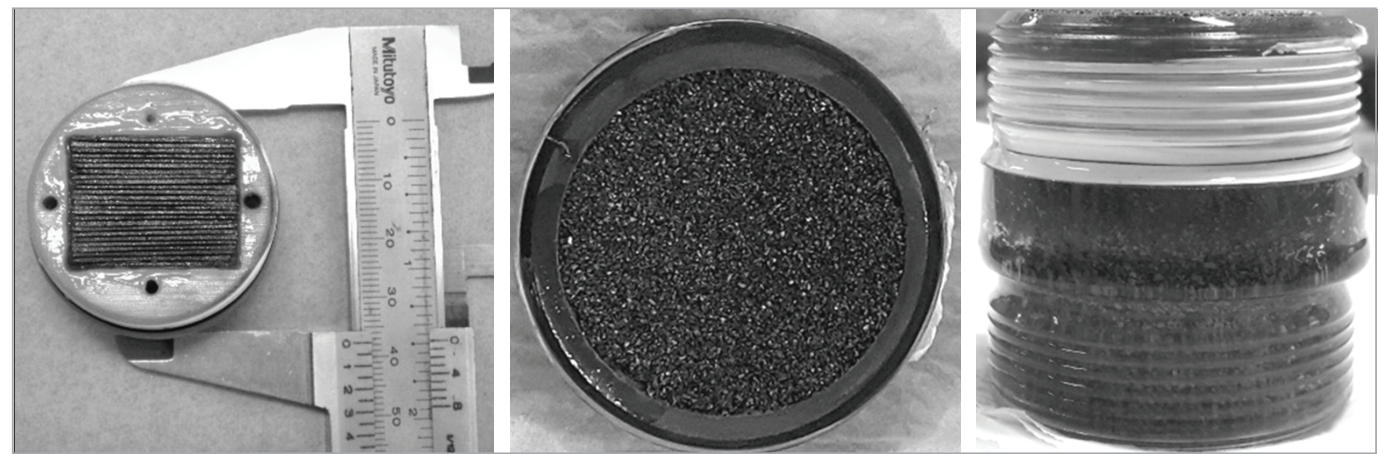

which is meant to maintain the mechanical integrity of the regenerator. A water based solution (2 $w t \%)$ of anti-corrosion inhibitor ENTEK FNE was used as a heat transfer liquid. All the samples have the same mass $(95 \mathrm{~g})$, and average specific heat $(500 \mathrm{~J} / \mathrm{kgK}$ ) (the difference in the specific heat of the samples might be neglected) (Neves Bez et al. 2016). The bonding epoxy has poorer thermal properties than pure MCM, nevertheless it is necessary for structural integrity of the regenerator. Thus it is important to measure the MCE characteristics of the regenerators before applying the material on a larger prototypes or magnetic heat pumps. Particularly this material is will be used in the ENOVHEAT (Efficient Novel Magnetocaloric Heat Pumps) prototype, which is under design at DTU Energy. More information can be found at the project's home page http:// www.enovheat.dk/.

In order to measure and log the temperature of the ambient, cold and hot end, the type E thermocouples and Pico TC-08 thermocouple data logger (Pico logger) were used.

The measurable temperature range for $\mathrm{E}$ type thermocouple is $-270+870{ }^{\circ} \mathrm{C}$. Standard accuracy is $+/-1.7^{\circ} \mathrm{C}$ or $+/-0.5 \%$.

A Pico logger has 8 channels for thermocouples and the cold junction compensation (CJC) measuring ambient temperature is used in this work. The features of the device are as follow:

_ measureable temperature range is $-270+1820^{\circ} \mathrm{C}$;

- temperature accuracy sum of $+/-0.2 \%$ of reading and $+/-0.5^{\circ} \mathrm{C}$;

_ voltage accuracy sum of $+/-0.2 \%$ of reading and $+/-10 \mathrm{mV}$;

_ conversion time $100 \mathrm{~ms}$ per thermocouple channel;

_ sampling rate is up to 10 samples per second;

resolution 20 bits.

\section{Results and discussion}

Fig. 5

No-load temperature span as a function of utilization for a two layers regenerator.
The optimal working point of the tested regenerators was at a piston amplitude of $20 \mathrm{~mm}$ and piston velocity $15 \mathrm{~mm} / \mathrm{s}$ $(\phi=0.45)$, see Fig. 5 and Fig. 6 . The working point was tested only for the sample of $2 \mathrm{wt} . \%$ epoxy. All of the presented samples kept their mechanical integrity during the tests, indicating that $2 \mathrm{wt} \%$ epoxy is adequate from a mechanical standpoint. The volume of the epoxy bonding the MCM particles was varied in order to find the minimum necessary amount to maintain the mechanical integrity of the regenerators. 
The regenerators with $3 \mathrm{wt} \%$ and $4 \mathrm{wt} \%$ of epoxy were tested at the same working point. As it was expected, the regenerator with $2 \mathrm{wt} \%$ of epoxy showed the best performance: $\Delta T_{\text {span }}=13.6 \mathrm{~K}$ at $T_{\text {hot }}=301 \mathrm{~K}$ $\left(28{ }^{\circ} \mathrm{C}\right)$. The peaks of the samples with $3 \mathrm{wt} \%$ and $4 \mathrm{wt} \%$ were $\Delta T_{\text {span }}=12.8 \mathrm{~K}$ (at $\left.T_{\text {hot }}=301 \mathrm{~K}\left(28^{\circ} \mathrm{C}\right)\right)$ and $\Delta T_{\text {span }}=12.2 \mathrm{~K}$ (at $\left.T_{\text {hot }}=300 \mathrm{~K}\left(27^{\circ} \mathrm{C}\right)\right)$, respectively.

The obtained results agree with the previously published knowledge and suggest that increasing the number of layers in the regenerator in the form of powders may lead to a broader temperature span (Eriksen 2016, Neves Bez et. al 2016). However, a more powerful and more efficient machine is necessary to allow us to perform a full test of multilayered regenerators. Thus, it is planned to build an advanced testing device with higher operating frequency and an adjustable magnetic field. The main purpose of the machine would be kept the same - to test and optimize active magnetic regenerators on a small scale before implementing them in larger, more complex prototypes, such as the rotary prototypes, built at DTU Energy (Bahl2013, Eriksen 2016). The design and arrangement of the machine is not well discussed yet, though. It is clear that the new device should be designed to be very flexible with regards to materials, regenerator geometry and operating conditions. Also, the available literature suggests that the temperature of a heat-sink must be decided a priori if a new device is going to be designed.

Finally, the efficiency and coefficient of performance (COP) of magnetocaloric prototypes has been significantly increased over the past three years - Okuamura and Hirano (2013) presented a device with a COP of 2.5 at a $\Delta T_{\text {span }}$ of $5 \mathrm{~K}$ of their previous prototype, later Jacobs et al. (2014) published results about a prototype, operating at a COP above 2 at a $\Delta T_{\text {span }}$ of $10 \mathrm{~K}$. The latest published prototype with a COP of 3.6 at a $\Delta T_{\text {span }}$ of $15.5 \mathrm{~K}$ and efficiency of $18 \%$ was developed at DTU Energy, it is described in Eriksen et al. (2016).

A brief introduction to the MCE as an alternative to the conventional vapor compression device has been given in the present paper. The existing test machine, built at DTU Energy, has been described. Additionally, the interested reader might find more information about the rotary prototype of the magnetic cooling technology in Eriksen (2016).

No-load temperature spans have been presented for the regenerators with varying amounts of bonding epoxy. It is seen that the smaller amount of epoxy in the volume of the regenerator, the better is the performance. The minimal amount of epoxy should be incorporated in order to sustain the mechanical integrity of the regenerator, though. As it is presented in the results section, the utilisation for all of the tested regenerators was $\phi=0.45$, which corresponded to a

\section{Fig. 6}

No-load temperature span as a function of fluid velocity for a two layers regenerator

\section{Fig. 7}

No-load temperature span as a function of the temperature of the hot end for a two layers regenerator. 
piston amplitude $20 \mathrm{~mm}$. The sample with the least amount of epoxy showed the best perform and temperature span $\Delta T_{\text {span }}=13.6^{\circ} \mathrm{C}$, while the sample with $4 \%$ of epoxy showed the lowest temperature span $\Delta T_{\text {span }}=12.2^{\circ} \mathrm{C}$. The regenerator with $3 \%$ of epoxy showed the temperature span of $\Delta T_{\text {span }}=12.8^{\circ} \mathrm{C}$.

The experiments on the same MCM with the $2 \%$ of epoxy will be continued in order to find the best configuration of the particles geometry and number of the layers in a regenerator.

\section{Acknow-}

The authors are grateful to Vacuumschmelze $\mathrm{GmbH}$ for providing the samples. This work was ledgment partly financed by the ENOVHEAT project which is funded by Innovation Fund Denmark (contract no 12-132673).

\section{References}

Bahl C. R. H. et al., Bonded LaFeSiH plates tested in a magnetocaloric device. International journal of refrigeration. 2016. In preparation.

Bahl C.R.H., Engelbrecht K., Eriksen D., Lozano J.A., Bjørk R., Geyti J., Nielsen K.K., Smith A., Pryds N. Development and experimental results from a $1 \mathrm{~kW}$ prototype AMR, Int. J. Refrigeration, 2013, 37:78. http://dx.doi.org/10.1016/j.ijrefrig.2013.09.001

Bahl C. R. H., Petersen T. F., Pryds N., Smith A. A versatile magnetic refrigeration test device. Review of scientific instruments, 2008, 79, 093906. http:// dx.doi.org/10.1063/1.2981692

Barbosa J,. Lozano J., Trevizoli P. Magnetocaloric refrigeration research at the INCT in cooling and thermophysics. $15^{\text {th }}$ Brazilian congress of thermal science and engineering, 2014. Conference proceedings.

Barclay J. A., Steyert W. A. Active magnetic regenerator. United States Patent. 1981. Application No. 228,836 .

Engelbrecht K., Bahl C. R. H., Nielsen K. K. Experimental results for a magnetic refrigerator using three different types of magnetocaloric material regenerators. International journal of refrigeration, 2011, 34: 1132-1140. http://dx.doi.org/10.1016/j. ijrefrig.2010.11.014

Engelbrecht K., Jensen J. B., Bahl C. R. H. Experiments on a modular magnetic refrigeration device. Journal of mechanical engineering 58, 2012, 1: 3-8.

Eriksen D. Active magnetic regenerator refrigeration with rotary multi-bed technology. PhD thesis submitted to DTU. 2016.

Eriksen D., Engelbrecht K., Bahl C. R. H. Bjørk R. Exploring the efficiency potential for an active magnetic regenerator. Science and technology for the built environment, 2016, 0:1-7.

Eriksen D., Engelbrecht K., Bahl C. R. H., Bjørk R., Nielsen K. K., Insinga A. R., Pryds N. Design and ex- perimental test of a rotary active magnetic regenerator prototype. International journal of refrigeration, 2015, 58: 14-21. http://dx.doi.org/10.1016/j. ijrefrig.2015.05.004

Jacobs S., Auringer J., Boeder A., Chell J., Komorowski L., Leonard J., Russek S., Zimm C. The performance o a large-scale rotary magnetic refrigerator. International journal of refrigeration, 2014, 37: 84-91. http://dx.doi.org/10.1016/j.ijrefrig.2013.09.025

Kaštil J., Tětek J., Tuček A. Experimental investigation of small-scale magnetocaloric refrigeration. Acta Physica Polonica A, 2013, 4 (124): 740-744. http://dx.doi.org/10.12693/APhysPolA.124.740

Kitanovski A., Tušek J., Tomc U., Plaznik U., Ožbolt M., Poredoš A. Magnetocaloric energy conversion from theory to application. Switzerland: Springer International publishing; 2015.

Lei Z., Haberstroh Ch., Odenbach S., Eckert K. Heat transfer enhancement in magnetic cooling by means of magnetohydrodynamic convection. International journal of refrigeration, 2016, 62: 166-176. http://dx.doi.org/10.1016/j.ijrefrig.2015.10.002

Neves Bez H., Navickaitè K., Lei T., Engelbrecht K., Barcza A., Bahl C. R. H. Epoxy-bonded $\mathrm{La}(\mathrm{Fe}, \mathrm{Mn}, \mathrm{Si}){ }_{13} \mathrm{H}_{z}$ as a multi layered active magnetic regenerator. Seventh IIF-IIR international conference on magnetic refrigeration at room temperature, ThermagVII, 2016. Submitted.

Nielsen K. K., Engelbrecht K. The influence of the solid thermal conductivity on active magnetgic regenerators. J Phys D Appl Phys, 2012, 45:145001. http:// dx.doi.org/10.1088/0022-3727/45/14/145001

Okamura T., Hirano N. Improvement of the performance of room temperature magnetic refrigerator using Gd-alloy. Journal of the Japan society of applied electromagnetics and mechanics, 2013, 21 (1):10-4. http://dx.doi.org/10.14243/jsaem.21.10 
Rowe A., Tura A. Experimental investigation of a three-material layered active magnetic regenerator. International journal of refrigeration, 2006, 29: 1286-1293. http://dx.doi.org/10.1016/j.ijrefrig.2006.07.012
Smith A., Bahl C. R. H., Bjørk R., Engelbrecht K., Nielsen K. K., Pryds N. Materials challenges for high performance magnetocaloric refrigeration device. Advance energy materials, 2012, 1-31.

\section{KRISTINA} NAVICKAITE

\section{PhD student}

Technical University of Denmark, Department of Energy Conversion and Storage, Section of Electrofunctional materials

\section{Main research area}

Heat transfer, renewable energy, fluid dynamic

\section{Address}

DTU Risø Campus, Frederiksborgvej 399, B 779, R15, 4000 Roskilde, Denmark Tel: +459351 1591 E-mail:knav@dtu.dk

\section{HENRIQUE NEVES \\ BEZ}

PhD student

Technical University of Denmark, Department of Energy Conversion and Storage, Section of Electrofunctional materials

\section{Main research area}

Material science, renewable energy

\section{Address}

DTU Risø Campus,

Frederiksborgvej 399, B 778, R19, 4000

Roskilde, Denmark Tel: +45 51308387

E-mail: hnbe@dtu.dk

\section{KURT} ENGELBRECHT

\section{Senior Researcher}

Technical University of Denmark, Department of Energy Conversion and Storage, Section of Electrofunctional materials

\section{Main research area}

Heat transfer, renewable energy, fluid dynamic, energy conversion

\section{Address}

DTU Risø Campus, Frederiksborgvej 399, B 779, R26, 4000 Roskilde, Denmark Tel: +45 46775649 E-mail:kuen@dtu.dk

\section{CHRISTIAN R. H.} BAHL

\section{Senior Researcher}

Technical University of Denmark, Department of Energy Conversion and Storage, Section of Electrofunctional materials

\section{Main research area}

Heat transfer, renewable energy, fluid dynamic, energy conversion, material science

\section{Address}

DTU Risø Campus, Frederiksborgvej 399, B 779, R26, 4000

Roskilde, Denmark Tel: +45 46775649

E-mail: chrb@dtu.dk

\section{About the} authors 